Annals of Pure and Applied Mathematics

Vol. 18, No. 1, 2018, 1-7

ISSN: 2279-087X (P), 2279-0888(online)

Published on 10 July 2018

Annals of

www.researchmathsci.org

DOI: http://dx.doi.org/10.22457/apam.v18n1al

Pure and Applied

Mathematics

\title{
On ve-degree Indices and their Polynomials of Dominating Oxide Networks
}

\author{
V.R.Kulli \\ Department of Mathematics \\ Gulbarga University, Gulbarga 585106, India \\ e-mail: vrkulli@gmail.com \\ Received 16 May 2018; accepted 7 July 2018
}

\begin{abstract}
Recently, the ve-degree concept is defined in Graph Theory. We introduce the first and second hyper-ve-degree indices of a molecular graph. Considering these hyperve-degree indices, we define the first and second hyper-ve-degree polynomials of a graph. We compute the first and second ve-degree Zagreb indices and their polynomials of dominating oxide networks. Also we compute the first and second hyper-ve-degree indices and their polynomials of dominating oxide networks.
\end{abstract}

Keywords: ve-degree indices, hyper-ve-degree indices, dominating oxide network

AMS Mathematics Subject Classification (2010): 05C05, 05C07, 05 C35

\section{Introduction}

Chemical Graph Theory is a branch of Graph Theory whose focus of interest is to finding topological indices of chemical graphs, which correlate well with chemical properties of the chemical molecules. A molecular graph is a simple graph related to the structure of a chemical compound. Each vertex of this graph represents an atom of the molecule and its edges to the bonds between atoms. Several topological indices have been considered in Theoretical chemistry, especially in QSAR and QSPR research, see [1].

Let $\mathrm{G}$ be a finite, simple connected graph with vertex set $V(G)$ and edge set $E(G)$. The degree $d_{G}(v)$ of a vertex $v$ is the number of vertices adjacent to $v$. The set of all vertices which adjacent to $v$ is called open neighborhood of $v$ and denoted by $N(v)$. The closed neighborhood set of $v$ is the set $N[v]=N(v) \cup\{v\}$. Let $S_{v}$ denote the sum of the degrees of all vertices adjacent to a vertex $v$. In [2], Chellali et al. defined the ve-degree concept in graph theory as follows:

Definition 1. The ve-degree $d_{v e}(v)$ of a vertex $v$ in a graph $G$ is the number of different edges that incident to any vertex from the closed neighborhood of $v$.

Recently, Ediz [3] introduced the first ve-degree Zagreb beta index of a graph $G$ and it is defined as

$$
V e_{1}(G)=S^{\beta}(G)=\sum_{u v \in E(G)}\left(d_{v e}(u)+d_{v e}(v)\right) .
$$


Also Ediz [3] introduced the second ve-degree Zagreb index of a graph $G$ and it is defined as

$$
V e_{2}(G)=S^{\mu}(G)=\sum_{u v \in E(G)} d_{v e}(u) d_{v e}(v) .
$$

Considering the ve-degree indices, we propose the first and second ve-degree polynomials of a graph $G$ as

$$
V e_{1}(G, x)=\sum_{u v \in E(G)} x^{d_{v e}(u)+d_{v e}(v)} .
$$

and

$$
V e_{2}(G, x)=\sum_{u v \in E(G)} x^{d_{v e}(u) d_{v e}(v)} \text {. }
$$

We introduce the first and second hyper-ve-degree indices of a graph $G$ as

$$
H V e_{1}(G)=\sum_{u v \in E(G)}\left(d_{v e}(u)+d_{v e}(v)\right)^{2}
$$

and $\quad H V e_{2}(G)=\sum_{u v \in E(G)}\left(d_{v e}(u) d_{v e}(v)\right)^{2}$.

Considering the hyper-ve-degree indices, we propose the first and second hyperve-degree polynomials of a graph $G$ as

$$
H V e_{1}(G, x)=\sum_{u v \in E(G)} x^{\left[d_{v e}(u)+d_{v e}(v)\right]^{2}} .
$$

and

$$
H_{V e}(G, x)=\sum_{u v \in E(G)} x^{\left[d_{v e}(u) d_{v e}(v)\right]^{2}} .
$$

The third ve-degree index of a graph $G$ is defined as

$$
V e_{3}(G)=\sum_{u v \in E(G)}\left|d_{v e}(u)-d_{v e}(v)\right| \text {. }
$$

Considering the third ve-degree index, we introduce the third ve-degree polynomial as

$$
V e_{3}(G, x)=\sum_{u v \in E(G)} x^{\left|d_{v e}(u)-d_{v e}(v)\right|} .
$$

Recently, some ve-degree topological indices were studied, for example, in $[4,5$, $6,7]$ and also several topological indices were studied, for example in $[8,9,10,11,12,13]$. Recently, some polynomials were studied, for example, in $[14,15,16,17,18,19,20$, $21,22,23,24,25]$.

We consider the family of dominating oxide networks [26,27]. In this paper, we determine the first and second ve-degree indices, the first and second hyper-ve-degree indices, the third ve-degree index for dominating oxide networks.

\section{Results for dominating oxide networks}

The family of dominating oxide networks is symbolized by $\operatorname{DOX}(n)$. The molecular structure of a dominating oxide network is presented in Figure 1. 
On ve-degree Indices and their Polynomials of Dominating Oxide Networks

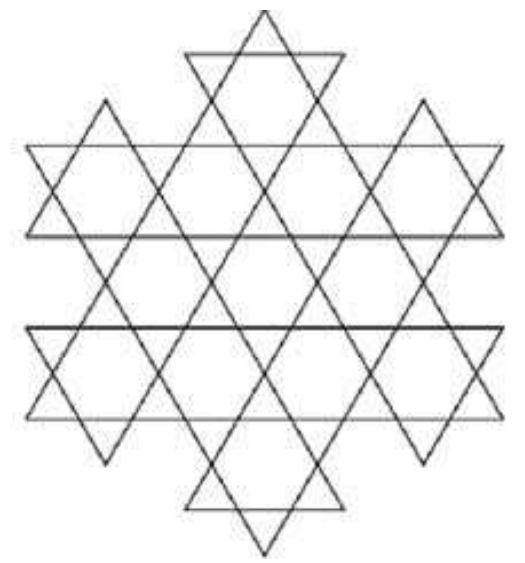

Figure 1: The structure of a dominating oxide network

In [8], Ediz obtained the partition of the edges with respect to their sum degree of end vertices of dominating oxide networks in Table 1.

\begin{tabular}{ccccccc}
\hline$\left(S_{u}, S_{v}\right)$ & $(8,12)$ & $(8,14)$ & $(12,12)$ & $(12,14)$ & $(14,16)$ & $(16,16)$ \\
\hline $\begin{array}{c}\text { Number of } \\
\text { edges }\end{array}$ & $12 n$ & $12 n-12$ & 6 & $12 n-12$ & $24 n-24$ & $54 n^{2}-114 n+60$ \\
\hline
\end{tabular}

Table 1:

Also he obtained the ve-degree partition of the end vertices of edges for dominating oxide networks in Table 2.

\begin{tabular}{ccccccc}
\hline $\begin{array}{c}\left(d_{v e}(u),\right. \\
\left.d_{v e}(v)\right)\end{array}$ & $(7,10)$ & $(7,12)$ & $(10,10)$ & $(10,12)$ & $(12,14)$ & $(14,14)$ \\
\hline $\begin{array}{c}\text { Number of } \\
\text { edges }\end{array}$ & $12 n$ & $12 n-12$ & 6 & $12 n-12$ & $24 n-24$ & $54 n^{2}-114 n+60$ \\
\hline
\end{tabular}

Table 2: The ve-degree of the end vertices of edges for $D O X$ networks

In the following theorem, we compute the values of $V e_{1}(D O X(n))$ and $\mathrm{Ve}_{2}(\operatorname{DOX}(n))$ for dominating oxide networks.

Theorem 1. The first ve-degree Zagreb beta index and second ve-degree Zagreb index of a dominating oxide network $D O X(n)$ are given by

(i) $\quad V e_{1}(D O X(n))=1512 n^{2}-1872 n+684$

(ii) $\quad V e_{2}(D O X(n))=10584 n^{2}-15024 n+5880$.

Proof: Let $G$ be the graph of a dominating oxide network $\operatorname{DOX}(n)$.

(i) Using equation (1) and Table 2, we deduce

$$
\begin{aligned}
& V e_{1}(\operatorname{DOX}(n))=\sum_{u v \in E(G)}\left(d_{v e}(u)+d_{v e}(v)\right) \\
& =(7+10) 12 n+(7+12)(12 n-12)+(10+10) 6+(10+12)(12 n-12) \\
& +(12+14)(24 n-24)+(14+14)\left(54 n^{2}-114 n+60\right) \\
& 3
\end{aligned}
$$


$=1512 n^{2}-1872 n+684$.

(ii) Using equation (2) and Table 2, we deduce

$$
\begin{aligned}
& V e_{2}(\operatorname{DOX}(n))=\sum_{u v \in E(G)} d_{v e}(u) d_{v e}(v) \\
& =(7 \times 10) 12 n+(7 \times 12)(12 n-12)+(10 \times 10) 6+(10 \times 12)(12 n-12) \\
& +(12 \times 14)(24 n-24)+(14 \times 14)\left(54 n^{2}-114 n+60\right) \\
& =10584 n^{2}-15024 n+5880
\end{aligned}
$$

In the following theorem, we determine the value of $\operatorname{Ve}_{1}(\operatorname{DOX}(n), x)$ and $\mathrm{Ve}_{2}(\mathrm{DOX}(n), x)$ for dominating oxide networks.

Theorem 2. The first and second ve-degree polynomials of a dominating oxide network $\operatorname{DOX}(n)$ are given by

$$
\begin{aligned}
V e_{1}(\operatorname{DOX}(n), x) & =12 n x^{17}+(12 n-12) x^{19}+6 x^{20}+(12 n-12) x^{22} \\
& +(24 n-24) x^{26}+\left(54 n^{2}-114 n+60\right) x^{28} \\
V e_{2}(\operatorname{DOX}(n, x)) & =12 n x^{70}+(12 n-12) x^{84}+6 x^{100}+(12 n-12) x^{120} \\
& +(24 n-24) x^{168}+\left(54 n^{2}-114 n+60\right) x^{196}
\end{aligned}
$$

Proof: Let $G$ be the graph of a dominating oxide network $\operatorname{DOX}(n)$.

(i) By using equation (3) and Table 2, we derive

$$
\begin{aligned}
& V e_{1}(D O X(n), x)=\sum_{u v \in E(G)} x^{d_{v e}(u)+d_{v e}(v)} \\
& =12 n x^{17}+(12 n-12) x^{19}+6 x^{20}+(12 n-12) x^{22}+(24 n-24) x^{26} \\
& +\left(54 n^{2}-114 n+60\right) x^{28} .
\end{aligned}
$$

(ii) By using equation (4) and Table 2, we derive

$$
\begin{aligned}
& V e_{2}(\operatorname{DOX}(n), x)=\sum_{u v \in E(G)} x^{d_{v e}(u) d_{v e}(v)} \\
& =12 n x^{70}+(12 n-12) x^{84}+6 x^{100}+(12 n-12) x^{120}+(24 n-24) x^{168} \\
& +\left(54 n^{2}-114 n+60\right) x^{196} .
\end{aligned}
$$

In the following theorem, we compute the first and second hyper-ve-degree indices of a dominating oxide network $\operatorname{DOX}(n)$.

Theorem 3. The first and second hyper-ve-degree indices of a dominating oxide network $D O X(n)$ are given by

(i) $H V e_{1}(D O X(n))=42336 n^{2}-59544 n-23076$

(ii) $\mathrm{HVe}_{2}(\mathrm{DOX}(n))=2074464 n^{2}-3470448 n-1430112$.

Proof: Let $G$ be the graph of dominating oxide network $\operatorname{DOX}(n)$.

(i) By using equation (5) and Table 2, we deduce

$$
\begin{aligned}
\operatorname{HVe}_{1}(\mathrm{DOX}(n)) & =(7+10)^{2} 12 n+(7+12)^{2}(12 n-12)+(10+10)^{2} 6+(10+12)^{2}(12 n-12) \\
& +(12+14)^{2}(24 n-24)+(14+14)^{2}\left(54 n^{2}-114 n+60\right) \\
& =42336 n^{2}-59544 n-23076
\end{aligned}
$$

(ii) By using equation (6) and Table 2, we derive

$$
\begin{aligned}
\mathrm{HVe}_{2}(\mathrm{DOX}(n)) & =(7 \times 10)^{2} 12 n+(7 \times 12)^{2}(12 n-12)+(10 \times 10)^{2} 6+(10 \times 12)^{2}(12 n-12) \\
& +(12 \times 14)^{2}(24 n-24)+(14 \times 14)^{2}\left(54 n^{2}-114 n+60\right) \\
& =2074464 n^{2}-3470448 n-1430112
\end{aligned}
$$


On ve-degree Indices and their Polynomials of Dominating Oxide Networks

In the following theorem, we determine the value of $\operatorname{HVe}_{1}(\operatorname{DOX}(n), x)$ and $\mathrm{HVe}_{2}(\operatorname{DOX}(n), x)$ for dominating oxide networks.

Theorem 4. The first and second hyper-ve-degree polynomials of a dominating oxide network are given by

$$
\begin{gathered}
\operatorname{HVe}_{1}(\operatorname{DOX}(n), x)=12 n x^{289}+(12 n-12) x^{361}+6 x^{400}+(12 n-12) x^{484} \\
+(24 n-24) x^{676}+\left(54 n^{2}-114 n+60\right) x^{784} \\
\operatorname{HVe}_{2}(\operatorname{DOX}(n), x)=12 n x^{70^{2}}+(12 n-12) x^{84^{2}}+6 x^{100^{2}}+(12 n-12) x^{120^{2}} \\
+(24 n-24) x^{168^{2}}+\left(54 n^{2}-114 n+60\right) x^{196^{2}}
\end{gathered}
$$

Proof: Let $G$ be the graph of a dominating oxide network $\operatorname{DOX}(n)$.

(i) By using equation (7) and Table 2, we derive

$$
\begin{aligned}
& H V e_{1}(D O X(n), x)=\sum_{u v \in E(G)} x^{\left[d_{v e}(u)+d_{v e}(v)\right]^{2}} \\
& =12 n x^{(7+10)^{2}}+(12 n-12) x^{(7+12)^{2}}+6 x^{(10+10)^{2}}+(12 n-12) x^{(10+12)^{2}} \\
& +(24 n-24) x^{(12+14)^{2}}+\left(54 n^{2}-114 n+60\right) x^{(14+14)^{2}} \\
& =12 n x^{289}+(12 n-12) x^{361}+6 x^{400}+(12 n-12) x^{484} \\
& +(24 n-24) x^{676}+\left(54 n^{2}-114 n+60\right) x^{784}
\end{aligned}
$$

(ii) By using equation (8) and Table 2, we derive

$$
\begin{aligned}
& \operatorname{HVe}_{2}(\operatorname{DOX}(n), x)=\sum_{u v \in E(G)} x^{\left[d_{v e}(u) d_{v e}(v)\right]^{2}} \\
& =12 n x^{70^{2}}+(12 n-12) x^{84^{2}}+6 x^{100^{2}}+(12 n-12) x^{120^{2}} \\
& +(24 n-24) x^{168^{2}}+\left(54 n^{2}-114 n+60\right) x^{196^{2}} .
\end{aligned}
$$

In the following theorem, we compute the third ve-degree index and its polynomial of dominating oxide network.

Theorem 5. The third ve-degree index and its polynomial of a dominating oxide network are given by

(i) $V e_{3}(\operatorname{DOX}(n))=168 n-132$.

(ii) $\operatorname{Ve}_{3}(\operatorname{DOX}(n), x)=(12 n-12) x^{5}+12 n x^{3}+(36 n-36) x^{2}+\left(54 n^{2}-114 n+60\right) x^{0}$.

Proof: Let $G$ be the graph of a dominating oxide network $\operatorname{DOX}(n)$.

(i) By using equation (9) and Table 2, we deduce

$$
\begin{aligned}
V e_{3}(\operatorname{DOX}(n))= & \sum_{u v \in E(G)}\left|d_{v e}(u)-d_{v e}(v)\right| \\
& =12 n \times 3+(12 n-12) 5+6 \times 0+(12 n-12) 2+(24 n-24) 2 \\
& +\left(54 n^{2}-114 n+60\right) 0 \\
& =168 n-132 .
\end{aligned}
$$

(ii) By using equation (10) and Table 2, we derive 


$$
\begin{aligned}
\text { V.R.Kulli } \\
\qquad e_{3}(\operatorname{DOX}(n), x)=\sum_{u v \in E(G)} x^{\left|d_{v e}(u)-d_{v e}(v)\right|} \\
=12 x^{3}+(12 n-12) x^{5}+6 x^{0}+(12 n-12) x^{2}+(24 n-24) x^{2} \\
+\left(54 n^{2}-114 n+60\right) x^{0} \\
=(12 n-12) x^{5}+12 n x^{3}+(36 n-36) x^{2}+\left(54 n^{2}-114 n+60\right) x^{0} .
\end{aligned}
$$

Acknowledgement. The author is thankful to the referee his/her useful suggestions.

\section{REFERENCES}

1. I.Gutman and O.E.Polansky, Mathematical Concepts in Organic Chemistry, Springer, Berlin (1986).

2. M.Chellali, T.W.Hynes, S.T.Hedetniemi and T.W.Lewis, On ve-degrees and evdegrees in graphs, Discrete Mathematics, 340(2) (2017) 31-38.

3. S.Ediz, Predicting some physicochemical properties of octane isomers: A topological approach using ev-degree and ve-degree Zagreb indices, International Journal of System Science and Applied Mathematics, 2(2017) 87-92.

4. B.Sahil and S.Ediz, On ev-degree and ve-degree topological indices, Iranian Journal of Mathematical Chemistry, in press.

5. V.R.Kulli, General multiplicative ve-degree indices of dominating oxide and regular triangulate oxide networks, Journal of Global Research in Mathematical Archives, 5(5) (2018) 60-64.

6. V.R.Kulli, Multiplicative connectivity ve-degree indices of dominating oxide and regular triangulate oxide networks, International Journal of Current Advanced Research, 7, 4(J) (2018) 11961-11964.

7. V.R.Kulli, Two new arithmetic-geometric ve-degree indices, Annals of Pure and Applied Mathematics, 17(1) (2018) 107-112.

8. I.Gutman, V.R.Kulli, B.Chaluvaraju and H.S.Boregowda, On Banahatti and Zagreb in indices, Journal of the International Mathematical Virtual Institute, 7(2017) 5367.

9. V.R.Kulli, On $K$ edge index of some nanostructures, Journal of Computer and Mathematical Sciences, 7(7) (2016) 373-378.

10. V.R.Kulli, A new Banhatti geometric-arithmetic index, International Journal of Mathmatical Archive, 8(4) (2017) 112-115.

11. V.R.Kulli, The sum connectivity Revan index of silicate and hexagonal networks, Annals of Pure and Applied Mathematics, 14(3) (2017) 401-406.

12. V.R.Kulli, On the product connectivity Revan index of certain nanotubes, Jounral of Computer and Mathematical Sciences, 8(10) (2017) 562-567.

13. V.R.Kulli, Reverse Zagreb and reverse hyper-Zagreb indices and their polynomials of rhombus silicate networks, Annals of Pure and Applied Mathematics, 16(1) (2018) 47-51.

14. V.R.Kulli, General Zagreb polynomials and F-polynomial of certain nanostructures, International Journal of Mathematical Archive, 8(10) (2017) 103-109.

15. V.R.Kulli, Certain topological indices and their polynomials of dendrimer nanostars, Annals of Pure and Applied Mathematics, 14(2) (2017) 263-268. 
On ve-degree Indices and their Polynomials of Dominating Oxide Networks

16. V.R.Kulli, Hyper Revan indices and their polynomials of silicate networks, International Journal of Current Research in Science and Technology, 4(3) (2018).

17. V.R.Kulli, General fifth M-Zagreb indices and fifth M-Zagreb polynomials of PAMAM dendrimers, International Journal of Fuzzy Mathematical Archive, 13(1) (2017) 99-103.

18. V.R.Kulli, Revan indices and their polynomials of certain rhombus networks, International Journal of Current Research in Life Sciences, 7(5) (2018) 2110-2116.

19. V.R.Kulli, F-Revan index and F-Revan polynomial of some families of benzenoid systems, submitted.

20. V.R.Kulli, Computing F-reverse index and F-reverse polynomial of certain networks, submitted.

21. V.R.Kulli, Computing the F-ve-degreeindex and its polynomial of dominating oxide and regular triangulate oxide networks, submitted.

22. V.R.Kulli, On augmented Revan index and its polynomial of certain families of benzenoid systems, submitted.

23. V.R.Kuuli, On augmented ve-degree index and its polynomial of dominating oxide and regular triangulate oxide networks, submitted.

24. V.R.Kulli, F-reverse index and F-reverse polynomial of certain families of benzenoid systems, submitted.

25. V.R.Kulli, Computing F-Revan index and F-Revan polynomial of certain networks, submitted.

26. S.Ediz, On ve-degree molecular topological properties of silicate and oxygen networks, Int. J. Computing Science and Mathematics, 9(1) (2018) 1-12.

27. F.Simonraj and A.George, Topological properties of few poly oxide, poly silicate, DOX and DSL networks, International Journal of Future Computer and Communication, 2(2) (2013) 90-95. 